\title{
Acolhimento às diferenças e temporalidades dos sujeitos: implicações curriculares na constituição do tempo escolar
}

\section{Reception of the differences and temporalities of the subjects: curricular implications in the constitution of school time}

\author{
Acogida de las diferencias y temporalidades de los \\ sujetos: implicaciones curriculares en la constitución \\ del tiempo escolar
}

Ana Sueli Teixeira de Pinho ${ }^{1}$

Elizeu Clementino de Souza ${ }^{1}$

DOI: http://dx.doi.org/10.20435/serie-estudos.v26i56.1488

\begin{abstract}
Resumo: O texto objetiva estabelecer relações entre o acolhimento às diferenças e temporalidades dos sujeitos, observando implicações curriculares daí emergentes e seus efeitos na constituição do tempo escolar. Do ponto de vista metodológico, adotaram-se princípios da pesquisa (auto) biográfica e a entrevista narrativa como dispositivo de pesquisa. No modelo curricular, ainda vigente, a expectativa é de que o sujeito internalize formas de controle do tempo, a fim de convertê-lo num corpo dócil e previsível, em relação a suas ações, de modo que todos se tornem parecidos, apesar de suas diferenças. Destacamos, como resultado da pesquisa, a necessidade de as políticas curriculares considerarem a reação do outro, que não se submete a um modelo curricular pronto, baseado na imposição de uma sincronização, com a justificativa de socialização, de inserção no mercado, de preparação para a vida e necessidade de acolhimento às diferenças e suas temporalidades, a fim de garantir a oportunidade de pensar a educação, a partir da coexistência e interação da diferença.
\end{abstract}

Palavras-chave: tempo escolar; acolhimento às diferenças; currículo.

Abstract: The text aims to establish relations between the reception of differences and temporalities of the subjects, observing the curricular implications that emerge from it and its effects on the constitution of school time. From a methodological point of view, the research adopted principles of (auto)biographical research and the narrative interview as a research device. In the curricular

${ }^{1}$ Universidade do Estado da Bahia (UNEB), Salvador, Bahia, Brasil. 
model, still in force, the expectation is that the subject internalizes forms of time control, in order to convert it into a docile and predictable body, concerning their actions, so that everyone becomes similar, despite their differences. We highlight, as a result of the research, the need for curricular policies to consider others reaction's, who doesn't submit to a ready curricular model, based on the imposition of synchronization, with the justification of socialization, insertion in the market, preparation for life, and the need to accept differences and their temporalities, in order to guarantee the opportunity to think about education, based on the coexistence and interaction of difference.

Keywords: school time; acceptance of differences; curriculum.

Resumen: El texto tiene como objetivo establecer las relaciones entre la acogida de las diferencias y temporalidades de los sujetos, muestra las implicaciones curriculares que emergen de él y sus efectos en la constitución del tiempo escolar. Desde el punto de vista metodológico, la pesquisa adoptó principios de investigación (auto)biográfica y de la entrevista narrativa como dispositivo de indagación. En el modelo curricular, aún vigente, la expectativa es que el sujeto internalice formas de control del tiempo, a fin de convertirlo en un cuerpo dócil y previsible en relación con sus acciones, de manera tal que, a pesar de sus diferencias, todos se tornen parecidos. Como resultado de la investigación, destacamos la necesidad de que las políticas curriculares consideren la relación con el otro, que el sujeto no se someta a un modelo curricular previamente elaborado, sustentado en la imposición de una sincronización, justificado tanto en la socialización como en la inserción en el mercado, o en la preparación para la vida, sino en la necesidad de acoger las diferencias y sus temporalidades con el fin de garantizar la oportunidad de pensar la educación a partir de la coexistencia e interacción con la diferencia.

Palabras clave: tiempo escolar; acogida de las diferencias; currículo.

\section{INTRODUÇÃO}

Este texto tem por objetivo estabelecer relações entre o acolhimento às diferenças e temporalidades dos sujeitos, observando implicações curriculares daí emergentes e seus efeitos na constituição do tempo escolar. É importante destacar que a categoria tempo escolar tem sido pouco problematizada nos estudos relacionados às políticas curriculares, uma vez que o modelo da escola graduada, em que currículo é estruturado como uma sequência linear de períodos ou idades que correspondem a uma sucessão, ou seja, uma ordem em que esta aprendizagem deve ocorrer, predomina ainda nas discussões sobre currículo.

O pressuposto assumido, no que se convencionou como forma de organização curricular, é que o progresso dos alunos é linear e que, por conta disso, deve ser natural que adquiram os conhecimentos exigidos e que são próprios da idade, num ritmo padrão ajustado ao tempo da escola. Quando se tomam as escolas rurais multisseriadas, cuja heterogeneidade é princípio que as fundamenta 
Acolhimento às diferenças e temporalidades dos sujeitos: implicações curriculares na constituição do tempo escolar

(PINHO, 2004), tal concepção aprofunda ainda mais o problema, na medida em que a própria organização e composição da turma não permitem a adoção da concepção curricular predominante na organização seriada.

Estudos realizados por Pinho (2012), Pinho e Souza $(2015$, 2017) reafirmam que, historicamente, o tempo escolar foi concebido a partir de um ritmo padrão que, na maioria das vezes, não dialoga com outros tempos sociais, situação que acarreta uma certa dificuldade em lidar com as temporalidades dos sujeitos. Essa forma de conceber o tempo escolar foi orientada por uma lógica homogeneizadora (das normas, dos espaços, dos tempos, dos alunos, dos professores, dos saberes e dos processos de inculcação). Tal princípio passou a constituir uma das características mais marcantes da "cultura escolar" (BARROSO, 1999) e passou a configurar a economia temporal que constituiu a escola: as formas de organização - seriação, multisseriação ou ciclos de aprendizagem; as marcações temporais, como ano letivo, semestres, unidades, dias, horas; e as faixas etárias das crianças. Enfim, uma concepção temporal guiada por relógios e calendários, que considera todos como se fossem um só, representados na figura da classe e do que se convencionou chamar de aluno médio.

A uniformização pretendida pela escola é muitas vezes traduzida como estratégia para neutralizar a presença de públicos cada vez mais diferenciados, decorrentes da transformação da escola "elitista" em escola de "massas", o que representou a invasão dos problemas sociais no interior da escola. As alternativas encontradas pela instituição escolar para driblar as diferenças dos alunos, reduzindo a complexidade emergente, consistem na busca de formas de homogeneizar os grupos escolares (CANÁRIO, 2010). Dessa forma, o controle parece mais fácil de ser conquistado.

Diante do exposto, este texto está organizado a partir da sua introdução, em que problematizamos o acolhimento às diferenças e temporalidades dos sujeitos, observando as implicações curriculares na constituição do tempo escolar. Em seguida, apresentamos os fios da trama narrativa com a explicitação das narrativas (auto)biográficas como abordagem metodológica, a entrevista narrativa como dispositivo de pesquisa e a análise compreensiva como perspectiva de análise das narrativas (auto)biográficas. Na sequência, discutimos as formas de classificação da diferença e o modo distorcido como o outro, muitas vezes, é reconhecido pela escola, e finalizamos com a reflexão sobre como o tempo escolar lida com as temporalidades dos sujeitos, assumindo este diálogo como (in)concluso e aberto. 


\section{OS FIOS DA TRAMA NARRATIVA}

As discussões aqui apresentadas são resultantes da pesquisa em duas escolas², a Escola Municipal de Botelho e a Escola Municipal de Praia Grande, ambas localizadas nas comunidades que lhes dão nome e situadas na Ilha de Maré, Salvador, BA. Foram realizadas 19 visitas à Ilha de Maré, durante todo o ano de 2011, assim distribuídas: uma visita para conhecimento e definição do campo empírico, 11 visitas à Escola Municipal de Botelho e 7 visitas à Escola Municipal de Praia Grande.

A pesquisa contou com a colaboração de quatro professoras em cada uma das escolas, todas elas residentes na própria comunidade em que atuam. Quanto aos demais colaboradores, a pesquisa contou com a participação de seis membros das comunidades, sendo quatro da localidade de Botelho e dois de Praia Grande.

Adotamos princípios da pesquisa (auto)biográfica e a entrevista narrativa como dispositivo de pesquisa, a partir de contribuições de SOUZA (2006a, 2006b) e Delory-Momberger (2008). A entrevista narrativa entendida como uma técnica específica de coleta e geração de dados assume um lugar de destaque na realização desta pesquisa, pois:

[...] através da narrativa, as pessoas lembram o que aconteceu, colocam a experiência em uma sequência, encontram possíveis explicações para isso, e jogam com a cadeia de acontecimentos que constroem a vida individual e social. (JOVCHELOVITCH; BAUER, 2007, p. 91).

Nesta perspectiva, o tempo se revela na trama da narrativa, e esta é constituída na relação com o outro. A identidade narrativa designa tanto o sujeito quanto a comunidade que ele integra, pois a narrativa das histórias de vida revela o entrecruzamento de vivências e pontos de interseção existentes entre eles. Como alerta SOUZA (2006a, p. 145), "o respeito pelas singularidades dos sujeitos, de suas histórias e das suas narrativas são princípios colocados para os sujeitos envolvidos desde o início do trabalho".

\footnotetext{
${ }^{2}$ A referida pesquisa insere-se no contexto do Projeto de Pesquisa intitulado "Multisseriação e Trabalho docente: diferenças, cotidiano escolar e ritos de passagem", financiada pelo CNPq e coordenada pelo Grupo de Pesquisa (Auto)biografia, Formação e História Oral, da Universidade do Estado da Bahia (GRAFHO/UNEB), desenvolvida em quatro escolas públicas do estado, sendo duas em Salvador - Ilha de Maré e Subúrbio Ferroviário- e duas em Amargosa.
} 
[...] o 'modelo interativo ou dialógico' adota uma nova relação de lugar entre o pesquisador e os atores sociais, tendo em vista uma co-construção de sentido, porque não é redutível à consciência que tem dela o sujeito e também à análise construída pelo pesquisador. (SOUZA, 2006b, p. 27).

Inicialmente, a intenção era realizar a pesquisa apenas com as professoras ${ }^{3}$ das duas escolas selecionadas. Acreditava-se que isso seria suficiente para atingir os objetivos da pesquisa; no entanto estas, ao narrarem suas experiências pessoais, remetiam-se a outros espaços e grupos sociais, diferentes da escola. A maré, por exemplo, era recorrente em suas narrativas, o que sugeriu a necessidade de inclusão de outras vozes ${ }^{4}$ : pescadores, marisqueiras e sujeitos das comunidades. Surgiam, assim, os primeiros indícios de que, para compreender o tempo escolar, era preciso levar em conta outros tempos sociais.

As entrevistas narrativas com as professoras foram desenvolvidas a partir da temática experiência de sala de aula, enfatizando a organização das atividades escolares. Foram informadas ainda de que, durante as entrevistas, não haveria interrupção com perguntas, que elas deveriam narrar livremente e que só no final, quando decidissem interromper, caso fosse necessário, seriam feitas algumas perguntas, a partir do que já havia sido narrado.

O uso de narrativa (auto)biográfica inscreve-se como pertinente, uma vez que ela é produzida por um sujeito social que, ao contar suas experiências de vida, "[...] faz referências a diversas pertenças sociais, a uma variedade de instituições: família, escola, trabalho, amigos, bairro de sua moradia, associações" (RHÉAUME, 2009, p. 167). Ou seja, esta narrativa se constitui como uma forma de expressão que é, simultaneamente, pessoal e social.

Uma maneira de interpretação de narrativas, destacada por Bertaux (2010) e aqui adotada, é a chamada análise compreensiva. Imaginação e rigor, segundo ele, estão na base desse tipo de análise, mas se prioriza a primeira. Grosso modo, o processo de imaginação, inicialmente mental e depois discursivo, consiste na

\footnotetext{
${ }^{3}$ Apesar de as professoras terem autorizado o uso de suas narrativas para o desenvolvimento da pesquisa, os nomes são fictícios, a fim de preservar as suas identidades. Os nomes adotados foram sugeridos pelas próprias professoras e serão antecedidos pela forma abreviada profa., a fim de distingui-las dos demais participantes da pesquisa.

${ }^{4}$ No caso dos pescadores, marisqueiras e outros membros das comunidades, foram utilizados os próprios nomes ou apelidos, antecedidos pela forma abreviada do pronome de tratamento; no caso em questão, Sr. e Sra.
} 
possibilidade de o pesquisador mobilizar "[...] os recursos interpretativos dos quais dispõe, que lhe ativam o conjunto do espaço cognitivo situado no interior do seu horizonte" (BERTAUX, 2010, p. 108).

Nessa perspectiva, a pesquisa desenvolvida fez ver que, quando se "olha" para o tempo escolar, melhor dizendo, para o tempo que atravessa o interior das duas escolas pesquisadas, diferentes fios aparecem entrelaçados a ele, que o torna problemático, tenso e complexo. Trata-se dos diferentes sujeitos, professores e alunos, que, ao mesmo tempo em que são representantes dos tempos sociais, são também construtores de suas próprias temporalidades.

\section{TEMPORALIDADES DOS SUJEITOS E CLASSIFICAÇÃO DADIFERENÇA: O RECONHECIMENTO DISTORCIDO DO OUTRO}

O que se pode observar no decorrer da pesquisa foi, de um lado, a dificuldade da escola em lidar com a diferença, o que a faz classificar e regular os comportamentos dos estudantes, impondo rótulos e estereótipos aos sujeitos, e, de outro, a adoção de estratégias que, de alguma forma, promovem o acolhimento e interações criativas e enriquecedoras entre eles, fazendo emergir a relação entre tempo e diferença. É importante ressaltar que a escola não é apenas um lugar de aprendizagem, mas se constitui também como um espaço de formação moral, impregnado de certas ideias e sentimentos; um ambiente que envolve os professores e alunos e os articula a um tempo específico.

Exemplo disso é quando a professora Bianca, ao comparar a sua trajetória escolar, na condição de aluna, com as experiências vivenciadas por seus alunos hoje, apresenta uma autoimagem positiva. Quando fala de si mesma, como aluna, destaca qualidades, tais como atitude investigativa, iniciativa, gosto pela leitura, caligrafia refinada, autonomia. Considera que foi uma boa aluna, apesar de ter morado numa comunidade com recursos escassos. Mesmo diante das dificuldades enfrentadas ao longo de seu processo formativo, ela considera ter iniciado muito cedo o segundo grau, hoje ensino médio, fato que atribui à sua força de vontade, perseverança e ao desejo de vencer.

Desde o início já tinha tendência a ser uma aluna pesquisadora, que buscava muito, e começava a ler os livros que minha mãe levava pra casa [...]. Tinha uma caligrafia muito bonita. Para o alfabetizador, a caligrafia ajuda, as redondas [...]. Era autodidata, buscava meu próprio conhecimento, em 
Acolhimento às diferenças e temporalidades dos sujeitos: implicações curriculares na constituição do tempo escolar

uma comunidade que não tinha recursos. Tudo pra mim era informação, era relevante, tudo que chegava na escola eu ia logo pegar, para contribuir na minha formação. Cada palestra, cada encontro, cada formação era muito significativa. Eu consegui concluir e com notas muito boas [...]. Comecei o meu segundo grau, tinha uns quinze anos, comecei cedo pra quem começou no projeto [...]. (Profa. Bianca, 2011).

Um aspecto que pode ser identificado na análise dessa narrativa corresponde ao modo como a professora relaciona as temporalidades do seu passado de aluna ao momento presente dos seus alunos. Dessa relação entre diferentes temporalidades, emerge uma representação implícita do Outro. De modo geral, ao resgatar a sua memória escolar, a professora levanta uma expectativa do que é ser aluno e apresenta uma imagem idealizada do outro, a partir de si mesma. Assim, ao prosseguir a narrativa, revela certa frustração com relação aos seus alunos de hoje:

Me desenvolvi muito rápido. Hoje os alunos têm acesso a tantas coisas, tantos métodos novos surgiram, tantas teorias, e os alunos demoram tanto de se alfabetizar, cada vez mais tarde. Eu tinha quatro a cinco anos e já era alfabetizada, já lia muito bem, com pontuação. Em sala de aula, já era auxiliar da professora. (Profa. Bianca, 2011).

O parâmetro adotado para a comparação é a duração do processo de alfabetização. A dela, descrita como rápida, e a de seus alunos, como demorada. Estranha que, apesar das condições favoráveis de seus alunos, esses aprendam mais lentamente. Ela, ao contrário, alfabetizou-se precocemente, lia bem a ponto de colaborar com a professora.

Essas representações evidenciam que o outro é percebido de maneira negativa, a partir do Mesmo, sendo colocado em situação de inferioridade, já que não atende a um conjunto de expectativas idealizadas, principalmente no que se refere ao tempo de aprendizagem. O Mesmo, tomado como referência, ou seja, a professora, na condição de aluna, é aquela que aprende mais cedo e mais rápido. Skliar (2003) nos ajuda a compreender essa relação entre o tempo e a mesmidade, quando afirma que:

Entre esse tempo conhecido e desconhecido, entre uma temporalidade repetida pelo mesmo e outra que foge (ou refoge) das leis da mesmidade, teriam de ser formuladas pelo menos duas grandes perguntas: a primeira, sobre o tempo enquanto relação com aquilo que chamamos realidade, 
nossa realidade, a realidade da mesmidade; a segunda sobre um tempo que parece apontar para um outro tempo, o tempo como diferença. (SKLIAR, 2003, p. 38).

As professoras Ana, Samara e Maria Quitéria fazem também representações do Outro, nesse caso, tomam os seus próprios alunos como referência. De modo geral, as representações reforçam as imagens distorcidas do Outro. Nas primeiras narrativas, o Outro é representado como aquele que tem dificuldade de aprendizagem. Essa ideia, além de estar associada a uma imagem errônea do Outro, refere-se também a uma relação problemática do aluno com o tempo. Lembrando que este aluno é simultaneamente representante de diferentes tempos sociais e construtor da sua própria temporalidade. Vejamos o que cada professora diz:

A idade atrapalha. Tem menino aqui, que ele já tem mais idade do que os outros e ele fica todo acanhado. Mas é a questão mesmo de dificuldade, ele não é nem um menino, assim pintão, nem nada, ele tem dificuldade mesmo. (Profa. Ana, 2011).

Tem criança que tem alguma deficiência na aprendizagem e nós professores não temos o direito de dizer qual é essa deficiência, mas algum especialista poderia afirmar isso. Nem todo mundo é igual, nós somos diferentes, independente de idade. Tem criança que até com cinco anos tem mais aprendizagem, chega mais rápido do que a de seis anos. (Profa. Samara, 2011).

Dos dezoito alunos, foram aprovados quatorze. Os que não foram aprovados é porque não acompanharam o desenvolvimento. Falta de interesse e algumas dificuldades também, que eles apresentam [...]. Estamos com alunos de quinto ano que, na verdade, se pode dizer que é terceiro ano. (Profa. Maria Quitéria, 2011).

Além dos alunos com "dificuldades de aprendizagem" desafiarem as professoras no desenvolvimento do seu trabalho, eles interferem negativamente na aprendizagem dos colegas:

Os alunos têm níveis diferentes [...]. Eles não prestam atenção e isso também acaba prejudicando os outros. Tenho aqui uns seis meninos que fazem toda a diferença na sala de aula. Prejudicam a sala. Não é pela idade, é mais pelo aprendizado mesmo. Tenho meninos bons aqui, mas tem meninos que não se interessam, aí prejudicam os outros. Os da tarde não, os do quarto ano são todos num nível só. Só tem quatro meninos, com menos avanço. Mas mesmo assim eles têm força de vontade, é questão mesmo da dificuldade 
Acolhimento às diferenças e temporalidades dos sujeitos: implicações curriculares na constituição do tempo escolar

que eles têm de aprender. Mas esses daqui, do terceiro ano, são pintões mesmo. Tem meninos maiores que não têm muito interesse, porque tá no meio de outros meninos menores [...]. (Profa. Ana, 2011).

Chama à atenção, nas narrativas das professoras, a recorrência da questão das "dificuldades de aprendizagem", expressão que não é neutra, remetendo a uma representação negativa do outro, como aquele que tem algum tipo de deficiência, de falta, de anormalidade. A expressão "dificuldade de aprendizagem" parece mascarar, de alguma forma, essas visões distorcidas, como se as professoras quisessem se esquivar das críticas às reais representações que esta expressão carrega. Buscando explicar essas dificuldades, recorre-se à fundamentação para as suas causas, sejam biológicas, sejam psicológicas ou emocionais:

Porque uma criança que tem dislexia é complicado, em sala de aula, ela conseguir se alfabetizar. Voltar e ficar a sós com ela, é um processo muito difícil, é um acompanhamento mais específico, que demanda tempo e muito empenho. Porque tem alunos que têm dificuldade de aprendizagem. Eles acabam sendo aprovados por conta do ciclo e chegam ainda no terceiro ano sem ler e sem escrever e com vários problemas de hiperatividade, TDA, TDAH, a gente consegue identificar [...] aquela criança que é hiperativa, que ela tem deficit de atenção. (Profa. Bianca, 2011).

As explicações para as causas das "dificuldades de aprendizagem" denotam a tentativa de dar a elas uma legitimidade científica. Impressiona a diversidade de diagnósticos para classificar as deficiências, sendo o indivíduo o responsável pela sua origem.

Já as professoras Liá, Bianca e Maria Quitéria apontam razões de natureza cultural, social e familiar:

A cultura, o modo de agir, de falar, tudo, de se vestir. Esse negócio deles não quererem se calçar, é difícil para mim, todo dia ter que tá tomando conta deles pra não tirar o chinelo do pé, a maneira de sentar, a postura. Eu dei um texto pra eles sobre a postura, porque a gente foi acostumado em outra realidade e, aos poucos, tô aprendendo a respeitar, a deixar eles. Eles têm dificuldade, mas isso não foi só agora, deveria ser trabalhado com eles desde o início. (Profa. Liá, 2011).

A criança é fruto do meio e se ela tiver em um meio saudável, cheio de esperança, de perspectivas, de novos horizontes, ela vai ser uma criança vencedora. Tem o aluno que, naquele dia, ele leu tudo, fez tudo; no outro dia, parece que deu um branco em casa, não sei o quê que acontece, que 
ele volta totalmente diferente [...]. Tenho alunos com vários problemas de deficits de aprendizagem. (Profa. Bianca, 2011).

Eu acho que eles têm que sonhar, meus alunos não sonham, não buscam objetivos. Por que a mãe dele tá indo todo dia pra maré, ele tem que seguir esse mesmo caminho? (Profa. Maria Quitéria, 2011).

Agora, o problema das "dificuldades de aprendizagem" não está mais centrado no indivíduo, mas no meio sociocultural em que ele se encontra inserido. É como se o imaginário social da comunidade ou o capital cultural familiar não favorecesse para que o aluno atribuísse sentido ao papel social da escola. Já a professora Bianca aponta razões pedagógicas:

[...] Eu percebo que muitos alunos, eles não adquiriram algumas bases na alfabetização infantil [educação infantil], que são muito relevantes, e por isso eles têm mais dificuldades na alfabetização, no primeiro ano, e o fato de ser ciclo também dificulta, pelo fato de que o aluno vai no ciclo de uma série pra outra, do primeiro ano pro segundo ano [...]. (Profa. Bianca, 2011).

Recorrendo a uma concepção de educação propedêutica, em que uma etapa serve de base para a outra, a professora Bianca explica as dificuldades de aprendizagem nos anos iniciais do Ensino Fundamental, devido a uma deficiência na Educação Infantil. Mais uma vez, o que está em jogo é a ampliação dos argumentos, para justificar os problemas de aprendizagem do outro.

As "dificuldades de aprendizagem", independentemente das causas apontadas, refletem-se de alguma forma em como o aluno se relaciona com o tempo escolar. É o que se pode deduzir das falas da professora Bianca:

Tem ritmo lento de aprendizagem, tem situações que o professor consegue lidar, na maioria, mas tem situações que esse ritmo muito lento é decorrente de alguma dificuldade de aprendizagem, é decorrente também de algum problema emocional, físico. (Profa. Bianca, 2011).

Vale a pena ir mais a fundo na discussão sobre as chamadas "dificuldades de aprendizagem", pois elas têm uma longa história, que vem se disseminando ao longo do tempo e influenciando por demais as práticas pedagógicas e os discursos dos professores no Brasil. Nesse sentido, as escolas da Ilha de Maré não constituem casos isolados. Além disso, essa disseminação tem contribuído para fortalecer as imagens estereotipadas acerca do aluno e de sua relação com o tempo escolar. 
Acolhimento às diferenças e temporalidades dos sujeitos: implicações curriculares na constituição do tempo escolar

A expressão "dificuldades de aprendizagem" parece ser análoga a "distúrbios de aprendizagem". Moysés e Collares (1992), ao estudarem esses tipos de distúrbio, já haviam identificado que:

[...] atualmente é comum o uso da expressão 'dificuldade de aprendizagem' para se referir ao mesmo conceito, provavelmente como meio para contornar a crítica. Porém, nada muda, em termos de referencial teórico e até mesmo do próprio nome; talvez se fale de uma alteração 'um pouco menos violenta' na aprendizagem, mas sempre localizada em quem aprende. (MOYSÉS; COLLARES, 1992, p. 31)

Do ponto de vista etimológico, os distúrbios de aprendizagem significam "anormalidade patológica por alteração violenta na ordem natural da aprendizagem" (MOYSÉS; COLLARES, 1992, p. 31) e estão situados no indivíduo, uma vez que não se referem a distúrbios no processo de ensino-aprendizagem.

Esses distúrbios, inicialmente, seriam provenientes de causas biológicas, o que pode ser interpretado como uma tentativa de biologização das questões sociais. Com o passar do tempo, esse tipo de explicação foi criticado por educadores e psicólogos, que passaram a atribuir aos problemas de aprendizagem causas de natureza psicológica. Para as autoras, debater se corresponde a um problema biológico ou psicológico é uma polêmica artificial, que desvia o foco principal da discussão, uma vez que ignora a própria história da construção da teoria sobre os distúrbios de aprendizagem.

Em primeiro lugar, é preciso reconhecer que os distúrbios de aprendizagem são uma construção do pensamento médico. Destacando a dislexia como um distúrbio decorrente de um problema neurológico, as autoras apontam que a sua identificação decorre do emprego de um "raciocínio clínico tradicional" ante os problemas sociais. Este é estruturado na origem da própria medicina como ciência, que obedece à seguinte lógica: "[...] se uma doença neurológica pode comprometer o domínio da linguagem escrita, será que a criança que não aprende a ler e escrever não teria uma doença neurológica?" (MOYSÉS; COLLARES, 1992, p. 33). Esse raciocínio marca o início, há quase um século, de uma história de equívocos e mitos em torno dos distúrbios de aprendizagem, não sendo estes acidentais.

Segundo as autoras Moysés e Collares (1992), os conceitos de disfunção cerebral mínima (DCM) e distúrbios de aprendizagem são vagos e carecem de precisão. Ao comparar as definições atribuídas aos distúrbios de aprendizagem, 
estabelecidas em 1968 e 1981 nos Estados Unidos, constatam que ainda que pretendesse objetividade, a última definição "[...] permite que qualquer criança com dificuldades na escola seja passível de enquadramento nesse diagnóstico" (MOYSÉS; COLLARES, 1992, p. 38).

Diante das fragilidades conceituais e da falta de comprovação empírica em torno dos distúrbios de aprendizagem, as autoras questionam a possibilidade de se identificar uma criança disléxica e como distingui-la de uma mal alfabetizada. Afirmam que "[...] termos como hiperativo, DCM, distúrbio, dislexia, hipercinético invadem o cotidiano da sala de aula, infiltram-se na fala dos professores" (MOYSÉS; COLLARES, 1992, p. 40).

Argumentam que essa forma de conceber os distúrbios de aprendizagem está relacionada a uma concepção de ciência e de mundo e, mais uma vez, questionam: "até que ponto uma criança [é considerada] esperta, ativa, estimulada, levada e a partir de que se torna patologicamente hiperativa?" (MOYSÉS; COLLARES, 1992, p. 42).

Ao responder a esta questão, elas assumem, como primeira certeza, que essas "doenças" só se manifestam quando a criança ingressa na escola. Quanto mais cedo se der o início da escolarização, mais cedo se poderia identificar a sua ocorrência. Outra percepção é que, entre as mães, é frequente a não observância da "doença" do filho até ele entrar na escola. Além de não observar, as mães não aceitam:

E quando vamos conversar com a mãe, que tem que procurar um CRAS, ela fica falando que o filho dela não é maluco, que não é doido. Isto é o que ela pensa e não o que a gente pensa. (Profa. Maria Quitéria, 2011).

Além dos alunos que demonstram alguma deficiência genética, e alguns pais, às vezes, não aceitam, a gente sempre chama, mas os pais se bloqueiam, não aceitam as deficiências. (Profa. Estrela, 2011).

Uma explicação possível para a disseminação desse arsenal de diagnósticos - hiperatividade, agressividade, distúrbio de aprendizagem, distúrbio de linguagem, incoordenação motora, deficit de concentração, instabilidade de humor, baixa tolerância a frustrações e outras menos comuns - é a tendência da sociedade de discriminar os comportamentos desviantes dos ditos normais. Uma outra explicação possível é que essa biologização venha ocorrendo, desde o século XIX, com o aval da ciência. 
Acolhimento às diferenças e temporalidades dos sujeitos: implicações curriculares na constituição do tempo escolar

As dificuldades de aprendizagem concebidas nessa perspectiva escamoteiam a dimensão social e pedagógica dos problemas educacionais e, ao mesmo tempo, desresponsabilizam o sistema social e a instituição escolar nele inserida. As crianças diagnosticadas como portadoras de distúrbios/dificuldades de aprendizagem, submetidas à medicalização, além dos efeitos químicos, enfrentam os efeitos subjetivos, pela possibilidade de internalização de estereótipos que repercutem na sua autoimagem, autoconceito, autoestima. E aquelas que não são medicalizadas também sofrem os efeitos perversos de um reconhecimento distorcido. Charles Taylor (2000) defende a tese:

[...] de que nossa identidade é moldada em parte pelo reconhecimento ou sua ausência, frequentemente pelo reconhecimento errôneo por parte dos outros, de modo que uma pessoa ou grupo de pessoas pode sofrer reais danos, uma real distorção, se as pessoas ou sociedade ao redor deles lhes devolverem um quadro de si mesmas redutor, desmerecedor ou desprezível. O não-reconhecimento ou reconhecimento errôneo podem causar danos, podem ser uma forma de opressão, aprisionando alguém numa modalidade de ser falsa, distorcida e redutora. (TAYLOR, 2000, p. 241).

Embora toda identidade seja negociada, contestada, aceita em parte ou totalmente, de fato pode ocorrer, como afirma Taylor (2000), a internalização de um reconhecimento distorcido, fazendo com que o outro tenha uma imagem negativa de si mesmo. Assim, ainda que o outro, o aluno, por exemplo, não apresente um quadro clínico que justifique determinado diagnóstico, o reconhecimento errôneo pode repercutir de modo perverso em sua relação com o tempo escolar.

Para o tratamento das diversas dificuldades de aprendizagem, há uma série de especialistas à disposição: psicopedagogo, psicólogo, fonoaudiólogo, fisioterapeuta, pediatra, professores de educação física e, também, pedagogos. A disseminação da dificuldade de aprendizagem na escola parece vir acompanhada da ideia de que o seu tratamento necessita do apoio de um ou vários especialistas. Não é à toa a expectativa das professoras Bianca e Estrela:

Aqueles que têm problemas de dificuldades de hiperatividade, o deficit de atenção, eles teriam acompanhamento com o núcleo, com uma rede de especialistas, como psicólogo, psiquiatra, pedagogo, psicopedagogo. Eles iam desenvolver atividades externas que iam fazer com que eles avançassem e conseguissem aprender. Em uma escola, muitas crianças têm dislexia e o professor não sabe; têm outros tipos de dificuldades que vão comprometer 
o processo de alfabetização dessa criança. Esse tempo assim extra, que a escola tira para as demandas externas, se fosse buscar em ações pedagógicas, relativas às dificuldades de aprendizagem, especificamente falando, com núcleo que acompanhasse e desse respaldo e subsídio aos professores para lidarem com isso, em um momento extra, eu acho que o rendimento seria outro e o ciclo seria outro também. (Profa. Bianca, 2011).

Depende de um psicopedagogo na escola, eu tenho esse sonho de ter um psicopedagogo aqui, para trabalhar esses alunos, o professor tem um lado que consegue, mas tem coisas que a gente vê, mas não pode afirmar, pois a nossa formação não permite. (Profa. Estrela, 2011).

Outra sugestão apontada é a necessidade de um espaço especial para atendimento aos alunos considerados com dificuldades de aprendizagem:

[...] se tivesse uma sala especifica pra essa criança se desenvolver, porque às vezes a criança tá hiperativa, a criança tá com deficit de atenção. Ainda que o professor faça várias atividades, nada vai atraí-lo, por conta da hiperatividade, não consegue sentar, se acalmar, ele é muito ativo. (Profa. Bianca, 2011).

A escola de tempo integral também aparece como uma alternativa para o tratamento da dificuldade de aprendizagem:

Se eu percebo que eu tenho uma turma e os alunos apresentam dificuldades, que o seu ritmo está muito lento e a aprendizagem não está acontecendo da forma que deveria, a escola deveria ser bem estruturada fisicamente, ela poderia ter um tempo integral pra essas crianças e, no horário oposto à aula, elas teriam acompanhamento e poderiam desenvolver essas habilidades, com mais calma, ter mais atenção. Porque uma sala, com vinte, não é o mesmo que uma sala com cinco, com quatro, com uma pessoa acompanhando, um professor. Escola integral, em tempo integral, seria uma sugestão boa! Esse tempo, oposto ao horário de aula, com essas atividades pra desenvolver habilidades que eles não alcançaram em decorrência de algum tipo de dificuldade de aprendizagem. Esse aluno teria um tempo extra pra aprender. E crianças com ritmos de aprendizagem que fossem relativos a algum problema de ordem psicológica, ou então física, ou emocional, iam ter mais tempo na escola, e teriam mais tempo de desenvolver habilidades que eles não estavam conseguindo em sala de aula. (Profa. Bianca, 2011).

As soluções apresentadas pelas professoras precisam ser contextualizadas, já que a sociedade espera delas o enfrentamento dos problemas difundidos pelo pensamento médico, que encontra na mídia um aliado de peso. Além disso, pelo 
fato de essas professoras se sentirem abandonadas e entregues à própria sorte pelo poder público, elas se consideram ainda mais responsáveis por dar uma solução a tais dificuldades.

Enfim, as imagens de reconhecimento distorcido dos alunos, pelas professoras, remetem à ideia do diferente, como o lento, lerdo, atrasado, com idade avançada, que tem, por sua vez, problema em acompanhar o tempo escolar. Geralmente é a lentidão, na execução das atividades escolares, a mais comum dessas expressões. Tanto o diagnóstico como as alternativas de solução referem-se à questão do tempo. Emerge daí uma reflexão importante sobre a relação entre tempo e ritmo.

Para compreender o sentido que o ritmo assume nas falas das professoras, é necessário considerar que ele aparece como um desdobramento das "dificuldades de aprendizagem". Como já foi argumentado aqui, essas dificuldades estão relacionadas à biologização da sociedade. Por isso, somos levados a defender que o ritmo está sendo compreendido como uma propriedade biológica do indivíduo.

\section{TEMPO ESCOLAR, DIFERENÇAS E CURRÍCULOS: DIÁLOGOS EM ABERTO E (IN)CONCLUSIVOS}

Por meio da análise das relações entre o acolhimento às diferenças e temporalidades dos sujeitos, das implicações curriculares daí emergentes e de seus efeitos na constituição do tempo escolar, deparamo-nos com uma concepção objetiva do tempo, tido, muitas vezes, como uma propriedade biológica do indivíduo, que deve estar sincronizado a um tempo que lhe é exterior. Nessa perspectiva temporal, o outro não é concebido como sujeito, espera-se, ao menos intencionalmente, sua passividade. Mas, ao contrário disso, o que se constata é que a ritmação esbarra na resistência e na insubmissão do outro.

Nas práticas educativas, propriamente ditas, a constatação pelas professoras de que os alunos têm ritmos totalmente diferentes pode ser tomada como um indício de que a tentativa de imposição de um tempo único, homogêneo, não se dá sem conflito ou tensão.

A emergência de uma outra concepção de tempo escolar, que supere a ideia de ritmo padrão e considere as temporalidades dos sujeitos, pressupõe o reconhecimento do outro como condição para a existência do tempo. Para tanto, 
alguns desafios talvez necessitem ser enfrentados:

a) a classificação abstrata do aluno;

b) a redução do sujeito à condição de aluno;

c) a dificuldade da escola em reconhecer a legitimidade do modo de vida da comunidade; e

d) o predomínio de uma concepção biunívoca de interação pedagógica.

Quanto ao primeiro desafio, há de se apontar, com base em Levinas (2011a), o esgotamento da representação como maneira de conhecer o outro, uma vez que o outro, na verdade, é irredutível a qualquer tentativa de representação. Ele se mantém Outro, independentemente da nossa competência representacional. Isso pressupõe uma abertura para que o outro diga quem ele é, mostre-se, ocupe o seu único lugar no mundo e exerça o seu direito de ser outro. Exemplos de representação problemática estão na classificação como forma de reconhecimento distorcido do outro. Não é de hoje que ela é utilizada por diferentes pedagogias. Essa classificação tem uma estreita ligação com os processos de biologização ou naturalização da sociedade. O reconhecimento do outro como o diferente desafia a escola que precisa lidar com diferentes outros.

Já em relação ao segundo desafio, a criança vivencia diferentes condições sociais, trata-se de uma pluralidade de experiências. Como sujeito, participa de várias expressões do viver. A vida na llha de Maré reveza-se entre estudar, ensinar-aprender, brincar, pescar, mariscar, festejar, contemplar, viajar, amar e por aí vai...

No que se refere ao terceiro, a Ilha se aproxima daquilo que Diegues (2004) chamou de maritimidade, um conjunto de diversas práticas (econômicas, sociais e, sobretudo, simbólicas) que decorrem da interação entre os seres humanos com um espaço singular e diferente do continental: o espaço da Ilha. Suas especificidades são legítimas e merecem ser reconhecidas e valorizadas. A escola tem dificuldade de reconhecer essa legitimidade, talvez pela sua relação historicamente direta com os valores e o modo de vida próprios do mundo urbano-industrial.

Quanto ao último desafio, numa relação biunívoca, tem-se a correspondência entre dois conjuntos, a cada elemento do primeiro corresponde um elemento do segundo, e vice-versa. Esse modelo de interação é por demais mecânico. Apesar de ser comum, essa não é a única forma de interação possível em sala de aula. Existem outras que possibilitam múltiplas relações, muito mais enriquecedoras. 
Acolhimento às diferenças e temporalidades dos sujeitos: implicações curriculares na constituição do tempo escolar

Enfrentar tais desafios pode significar o ponto de partida para se pensar uma escola em que o outro se sinta mais bem acolhido na sua diferença. Fazendo analogia dessa escola com a "casa de Levinas", como argumentou Milovic (2004), onde esse outro poderá se sentir acolhido?

[...] onde esconder-se neste mundo perigoso, onde encontrar lugares seguros? Seguramente não na casa de um utilitarista cujo cálculo nos pode extraditar os criminosos. Não na casa de um kantiano que sempre tem de dizer a verdade. Eu teria muitas dúvidas sobre a casa de um habermasiano, porque tudo pode acontecer com a nossa vida até encontrarmos uma solução discursiva. Teria também muitas dúvidas na casa de um pós-moderno, orientado pela perfeição estética da sua própria vida. (MILOVIC, 2004, p. 119-20).

Então, que lugar é esse? "O único lugar seguro parece a casa de Levinas aberta para Outrem, essa casa que nos oferece hospitalidade sem reciprocidade, além da influência econômica" (MILOVIC, 2004, p. 120). No entanto, adverte Milovic (2004), "casa" aqui não é "[...] um espaço real, porque o espaço remete à metafísica da presença. Temos de neutralizar o espaço para abrir a possibilidade do tempo. Com a afirmação do Outro, abre-se o futuro, a perspectiva do tempo, da história" (MILOVIC, 2004, p. 120).

Ao remeter essa ideia de encontro com o Outro, sem confundir esse encontro com fusão ou harmonia, mas entendê-lo como diferença, somos levados a pensar a educação como um ato não apenas ético, mas também político. A política aqui é pensada no sentido atribuído por Rancière (1996), como acontecimento, como manifestação do dissenso, como desentendimento. Essa ideia se aproxima do conceito de política de Levinas (2011a), que a considera como afirmação da diferença.

Política, em Rancière (1996), é acontecimento; acontecimento, em Levinas (2011a), é tempo. Nesse sentido, pode-se afirmar que o tempo do encontro com o outro é acontecimento, em que eu e o outro interagimos, coexistimos, mas nos mantemos afastados. Se a condição do tempo é a relação inter-humana, uma relação simultânea, como pensar o tempo escolar? Como promover a conciliação entre socialização e subjetivação? Como dar a chance ao Outro de aprender mais uma forma de se relacionar com o tempo, o do relógio, para viver na sociedade contemporânea, em que muitas práticas sociais estão imbricadas, sem desconsiderar tantas outras formas de se relacionar com o tempo? Vale a pena retomar a 
discussão para dizer um pouco mais sobre a importância das ideias de coexistência e interação com o outro.

Seguindo esta pista, retomamos a reflexão bakhtiniana sobre a relação complexa entre compenetração e acabamento, no âmbito das práticas de interação humana. Apesar de Bakhtin (2003) se referir à atividade artístico-literária, aqui nos interessa pensar o campo da educação.

A compenetração é o primeiro momento da atividade estética, afirma Bakhtin (2003). Em relação ao Outro, "[...] devo vivenciar - ver e inteirar-me - o que ele vivencia, colocar-me no lugar dele como que coincidir com ele [...]. Devo adotar o horizonte vital concreto desse indivíduo, tal como ele o vivencia". Mas, alerta Bakhtin, "[...] a compenetração pura, vinculada à perda do nosso único lugar fora do Outro, é quase impossível e, em todo caso, totalmente inútil e sem sentido" (BAKHTIN, 2003, p. 23-4).

O acabamento, essa outra dimensão das atividades ética e estética, começa quando estamos de volta a nós mesmos, ao nosso lugar fora do Outro. Esse excedente da visão estética, "[...] só eu posso praticar em relação ao outro, a quem elas são inacessíveis no lugar que ele ocupa fora de mim [...]" (2003, p. 23). Essas duas ações de compenetração e acabamento são infinitamente variáveis, dependendo das situações da vida. E, além disso, não se sucedem de modo cronológico, são ações intimamente entrelaçadas, por assim dizer, inseparáveis.

Mas não se pode esquecer das advertências de Faraco (2010) sobre a crítica do próprio Bakhtin à visão estética ou ao esteticismo. Em outras palavras, a visão estética se justifica:

[...] se não ultrapassar suas próprias fronteiras. Se ao invés disso, ela tem a pretensão de ser uma visão do existir único e singular na sua eventicidade, então ela é condenada a apresentar uma parte abstratamente isolada como se fosse o todo efetivo. (FARACO, 2010, p. 152).

Aproximando a reflexão de Bakhtin (2003) para a educação, é possível afirmar que reconhecer o aluno não significa abandonarmos o nosso lugar de professor. Pelo contrário, diante do outro, o aluno, devemos assumir o lugar único que ocupamos perante ele. Daí a necessidade do duplo movimento que ocorre no tempo do encontro, a compenetração e o acabamento.

Diante das provocações de Bakhtin (2003) e Levinas (2011a, 2011b), o tempo escolar, como tempo do encontro com o Outro, marcado pela 
imprevisibilidade, pelo risco, pela aventura e pela abertura, pode possibilitar um duplo enriquecimento, o do professor e o do aluno, que passam a ver, nas tensões interativas, oportunidades de fazerem dialogar e coexistir diferentes visões de mundo.

Essa concepção de tempo escolar, como acontecimento, como simultaneidade, contribui para repensar o lugar do professor, que não se restringe, claro, a reconhecer o outro tal como ele é, diferente. O professor passa a ser aquele que, diante dos seus alunos, não abre mão do seu lugar no mundo.

Pensar a educação nessa perspectiva é superar a ideia de trabalho sobre os outros, pela ideia de trabalho com os outros, em que o professor assume o lugar de instaurador da discursividade sobre temas, conhecimentos, saberes e situações que contribuam para o processo de inserção dos seus alunos no mundo. Isso significa assumir diante do outro uma posição diferente da do mero informante, mas aquele que expressa valoração ético-estética do mundo do outro. Por outro lado, esse encontro, que não abre mão do lugar exotópico do professor, pressupõe abertura para o risco, a incerteza, a insegurança, a contestação, o conflito e o dissenso.

Enfim, a partir das reflexões aqui apresentadas, chama à atenção o silenciamento dos estudos relacionados ao currículo sobre a questão do tempo escolar. As definições das políticas curriculares precisam levar em consideração, de um lado, a reação do outro, que não se submete a um modelo curricular pronto, baseado na imposição de uma sincronização, com a justificativa de socialização, de inserção no mercado, de preparação para a vida, e, de outro lado, a necessidade de acolhimento às diferenças e temporalidades dos sujeitos, para não se perder a oportunidade de pensar a educação, a partir do reconhecimento do outro. Não parece fazer sentido afirmar que o outro quer abrir mão da educação escolar. $\mathrm{Na}$ verdade, ele quer ter assegurado o seu direito à educação, mas sem abrir mão do seu lugar de outro.

\section{REFERÊNCIAS}

BAKHTIN, Mikhail. Estética da criação verbal. Tradução de Paulo Bezerra. São Paulo: Martins Fontes, 2003.

BARROSO, João. Da cultura da homogeneidade à cultura da diversidade: construção da autonomia e gestão do currículo. In: MENDES, Maria Luísa Sobral. (Coord.). Fórum: 
escola diversidade e currículo. Lisboa: Departamento da Educação Básica - Ministério da Educação, 1999. p. 79-92.

BERTAUX, Daniel. Narrativas de vida: a pesquisa e seus métodos. Tradução de Zuleide Alves Cardoso Cavalcante e Denise Maria Gurgel Lavallée. 2. ed. São Paulo: Paulus, 2010.

CANÁRIO, Rui. Escolas: elogio da diversidade. In: CANÀRIO, Rui. 30 olhares para o futuro. São Paulo: Escola da Vida 30 anos, 2010. p. 251-5.

DELORY-MOMBERGER, Christine. Biografia e educação: figuras do indivíduo-projeto. Tradução e revisão científica: Maria da Conceição Passeggi e João Gomes da Silva Neto. São Paulo: Paulus, 2008.

DIEGUES, Antônio Carlos. A pesca construindo sociedades: leituras em antropologia marítima e pesqueira. São Paulo: NUPAUB, 2004.

FARACO, Carlos Alberto. Um posfácil impertinente. In: BAKHTIN, Mikhail. Por uma filosofia do ato responsável. São Carlos: Pedro \& João editores, 2010. p. 147-58.

JOVCHELOVITCH, Sandra; BAUER, Martin W. Entrevista Narrativa. In: BAUER, Martin W.; GASKELL, George. Pesquisa qualitativa com texto, imagem e som: um manual prático. Tradução de Pedrinho Guareschi. 6. ed. Petrópolis: Vozes, 2007. p. 90-113.

LEVINAS, Emmanuel. Totalidade e infinito. Tradução de José Pinto Ribeiro. Lisboa: Edições 70, 2011a.

LEVINAS, Emmanuel. Le temps et l'autre. Paris: Presses Universitaires de France, 2011b.

MILOVIC, Miroslav. Comunidade da diferença. Rio de Janeiro: Relume Dumará, 2004.

MOYSÉS, Maria Aparecida Affonso; COLLARES, Cecília Azevedo Lima. A história não contada dos distúrbios de aprendizagem. In: SMOLKA, Ana Luiza B.; BRYAN, Newton A. P. (Org.). O sucesso escolar: um desafio pedagógico. Campinas: Papirus, 1992. (Caderno CEDES, 28). p. 31-47.

PINHO, Ana Sueli Teixeira; SOUZA, Elizeu Clementino. Fios que Tecem o Tempo Escolar: do ritmo padrão à simultaneidade. Educação e Realidade, Porto Alegre, v. 42, n. 3, p. 1-22, 2017. (Edição eletrônica)

PINHO, Ana Sueli Teixeira; SOUZA, Elizeu Clementino. O tempo escolar e o encontro com o outro: do ritmo padrão às simultaneidades. Educação e Pesquisa, São Paulo, v. 41, n. 3, p. 663-78, 2015. 
Acolhimento às diferenças e temporalidades dos sujeitos: implicações curriculares na constituição do tempo escolar

PINHO, Ana Sueli Teixeira. O tempo escolar e o encontro com o outro: do ritmo à simultaneidade. 2012. 274 f. Tese (Doutorado em Educação e Contemporaneidade) Universidade do Estado da Bahia, Salvador, 2012.

PINHO, Ana Sueli Teixeira. A heterogeneidade fundante das classes multisseriadas do meio rural: entre a persistência do passado e as imposições do presente. 2004. $178 f$. Dissertação (Mestrado em Educação e Contemporaneidade) - Universidade do Estado da Bahia, Salvador, 2004.

RANCIÈRE, Jacques. O desentendimento: política e filosofia. Tradução de Ângela Leite Lopes. São Paulo: Editora 34, 1996.

RHÉAUME, Jacques. Relato de vida coletivo e empoderamento. In: TAKEUTI, Norma Missae; NIEWIADOMSKI, Christophe. (Org.). Reinvenções do sujeito social: teorias e práticas biográficas. Porto Alegre: Sulina, 2009. p. 166-188.

SKLIAR, Carlos. Pedagogia (improvável) da diferença e se o outro não estivesse aí? Tradução de Giane Lessa. Rio de Janeiro: DP\&A, 2003.

SOUZA, Elizeu Clementino. Pesquisa narrativa e escrita (auto) biográfica: interfaces metodológicas e formativas. In: SOUZA, Elizeu Clementino; ABRAHÃO, Maria Helena Menna Barreto. (Org.). Tempos, narrativas e ficções: a invenção de si. Porto Alegre: EDIPUCRS, 2006a. p. 135-147.

SOUZA, Elizeu Clementino. A arte de contar e trocar experiências: reflexões teóricometodológicas sobre história de vida em formação. Revista Educação em Questão, Natal, v. 25, n. 11, p. 22-39, jan./abr. 2006b.

TAYLOR, Charles. Argumentos filosóficos. Tradução de Adail Ubirajara Sobral. São Paulo: Edições Loyola, 2000.

\section{Sobre os autores:}

Elizeu Clementino de Souza: Doutor e mestre em Educação pela Faculdade de Educação da Universidade Federal da Bahia (FACED/UFBA). Graduado em Pedagogia pela Universidade Católica de Salvador. Pesquisador 1C CNPq. Professor titular do Programa de Pós-Graduação em Educação e Contemporaneidade pela Universidade do Estado da Bahia (PPGEduC-UNEB). Coordenador do Grupo de Pesquisa (Auto)biografia, Formação e História Oral (GRAFHO/UNEB). Pesquisador 
associado do Laboratoire EXPERICE (Université de Paris 13-Paris 8). Tesoureiro da Associação Brasileira de Pesquisa (Auto)biográfica (BIOgraph). Diretor financeiro da ANPEd (2013-2015). Membro do Conselho de Administração da Association Internationale des Histoires de Vie en Formation et de Recherche Biographique en Education (ASIHIVIF-RBE). Editor da RBE/ANPEd, RBPAB e da Revista da FAEEBA. E-mail: esclementino@uol.com.br, Orcid: http://orcid.org/0000-0002-4145-1460 Ana Sueli Teixeira de Pinho:, Mestre e doutora em Educação e Contemporaneidade pelo Programa de Pós-Graduação em Educação da Universidade do Estado da Bahia (UNEB). Graduada em Pedagogia pela Universidade Católica do Salvador. Pesquisadora do Grupo de Pesquisa (Auto)biografia, Formação e História Oral (GRAFHO/UNEB). E-mail: anasuelipinho@yahoo.com.br, Orcid: http://orcid.org/0000-0003-3644-954X

Recebido em: 31/07/2020

Aprovado em: 17/09/2020 